\title{
Tracheostomy - when best to perform
}

\author{
Arunachalam Soma, 2nd year medical student, Shadaba Ahmed FRCS, ORL-HNS
}

\begin{abstract}
Tracheostomy is a procedure that is performed for various indications, including relieving an upper airway obstruction, removing secretions and preventing laryngeal and upper airway damage from prolonged translaryngeal intubation. The latter is a significant factor recognised by clinicians, and hence as soon as the need for prolonged mechanical ventilation is identified, tracheostomy should be considered. However, the challenge lies in identifying who would require prolonged ventilatory support. Hence, this structured review explores the debate between early versus late tracheostomy and investigates the predictive factors that indicate prolonged mechanical ventilation and a subsequent tracheostomy. The included studies highlighted a reduction in the duration of sedation, a shorter stay in the intensive care unit (ICU), and a shorter weaning time in patients with an early tracheostomy. Although there was no significant reduction in ventilator-associated pneumonia or mortality rates, the above-mentioned advantages suggest that performing a tracheostomy on a patient early in the course of their illness may prove beneficial. However, the predictive power of the factors that could indicate prolonged mechanical ventilation were poor. Hence, there were no objective guidelines to aid clinicians' decisions of an early tracheostomy other than their own clinical judgement. Therefore, this structured review illustrated that this decision was varied to each individual.
\end{abstract}

\section{INTRODUCTION}

Tracheostomy is a common surgical procedure performed in critically ill patients who require prolonged mechanical ventilation (MV). This could be due to airway issues or acute respiratory failure. ${ }^{1}$ The initial step, before implementing a tracheostomy, is placing a translaryngeal tube to assist with the patient's breathing. Translaryngeal intubation (TI) is the insertion of an artificial airway into the trachea. This involves passing a tube via the mouth or nose, through the larynx into the trachea. ${ }^{2}$ However, having a TI for a prolonged time has its consequences, which will be discussed later. Hence, a tracheostomy is performed after TI, if a patient remains on MV. Medical indications for a tracheostomy include unrelieved upper airway obstruction, need for lengthened MV, secretion removal, airway protection, and avoidance of complications from prolonged use of TI. Other indications include decreased level of consciousness and trauma. It is also known to increase patient safety and comfort. ${ }^{3}$

A clinician's decision to perform a tracheostomy is multi-factorial, looking at expected recovery course, risk of prolonged TI and surgical dangers of tracheostomy ${ }^{3}$. Not only is whether to perform a tracheostomy in the debate, so is when to perform one along the course of a patient's illness. Moreover, the timing of tracheostomy has changed over the past few years. In the 1980s, it was considered 'early' if it was done before 21 days of TI. However, in recent otorhinolaryngology literature, it has been recommended to perform a tracheostomy within 3-7 days of TI. ${ }^{4}$ This is because there is mucosal damage to the larynx after 3 days of intubation. ${ }^{3}$

However, one should consider the magnitude of this procedure - of its risks and post-operative consequences. These in the short-term may include bleeding and skin infection, and in the long-term may include disfiguring neck scars and vocal injury. ${ }^{5}$ Thus, rushing into an early decision to perform a tracheostomy would ignore weighing up the long-term consequences on the patient. Hence, it is vital for clinicians to identify those who may require prolonged ventilatory support, and then use this to decide who would need a tracheostomy.

The aim of this structured review therefore is to explore the differences in outcomes between early and late tracheostomy. In addition, to investigate if there is a method or any predictive factors to determine which patient would require prolonged $\mathrm{MV}$, and hence a tracheostomy. This could prove essential to clinicians when dealing with such a serious procedure, which has both short- and long-term complications.

\section{TRACHEOSTOMY - BACKGROUND}

The lower respiratory tract, which is of more relevance to the tracheostomy procedure, begins at the vocal cords. Certain key superficial anatomical landmarks are the hyoid bone, thyroid and cricoid cartilages that are positioned around the larynx. ${ }^{9}$ Inferior to the cricoid cartilage is the trachea. It consists of around $20 \mathrm{C}$-shaped cartilage rings, with the first few being of importance to different methods of performing a tracheostomy (refer to Fig. 1). ${ }^{9}$

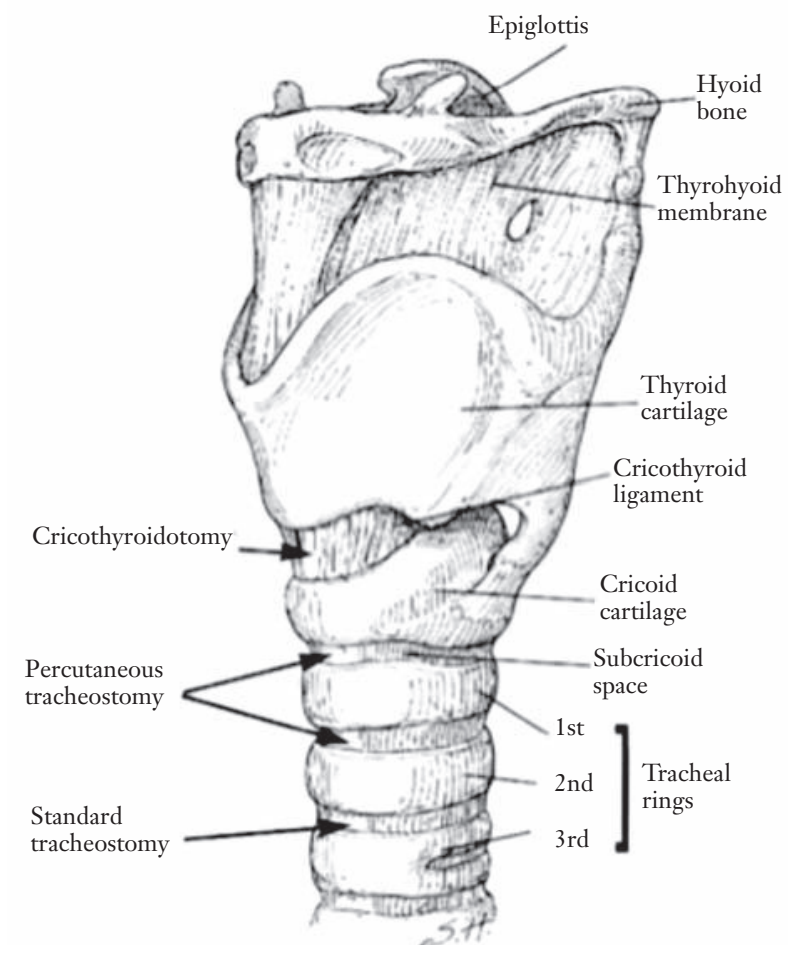

Figure 1: Oblique view of the anterior larynx and trachea with the anatomical locations for placing different types of tracheostomy (figure taken from reference 9) 
Furthermore, a group of muscles called the strap muscles - sternohyoid, sternothyroid, and sternocleidomastoid, protects it (refer to Fig. 2). The trachea is located posterior to the thyroid isthmus and a number of blood vessels including branches of the inferior thyroid. ${ }^{9}$

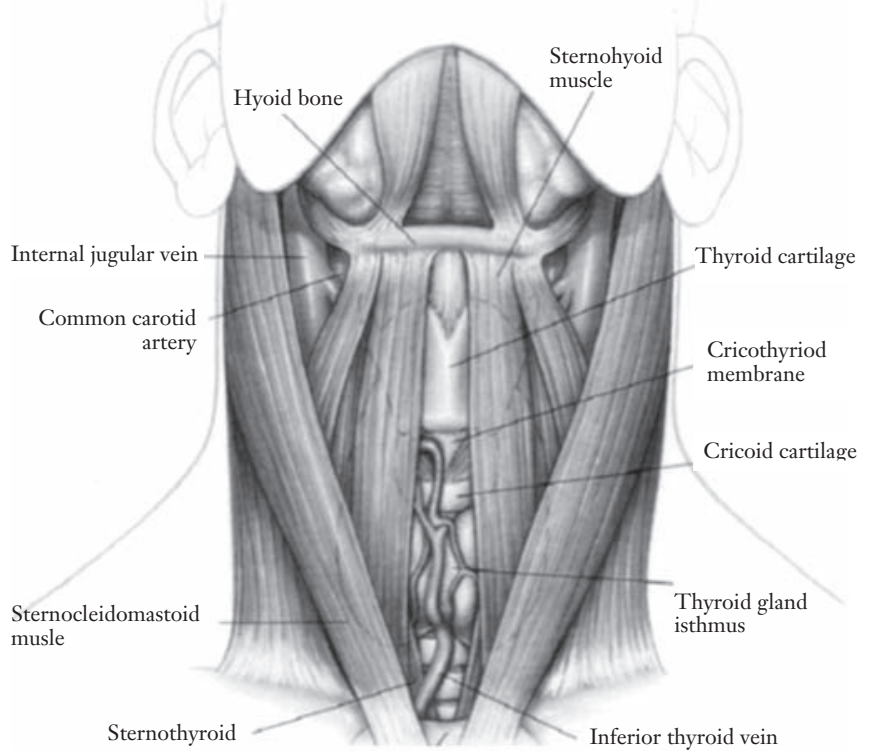

Figure 2: Major anatomical landmarks in the neck region (figure taken from reference 9)

Certain functional concepts that pertain to the procedure of a tracheostomy include humidification and airflow resistance. The normal physiology involves the nose and the upper tract warming and humidifying the inspired air to maintain constant lung conditions. ${ }^{10}$ However, with a tracheostomy tube, it bypasses the nasal and upper airway. Hence, this leads to a loss of heat and moisture during ventilation. It could also lead to the trachea developing chronic inflammatory changes leading to squamous metaplasia. Therefore, air must be humidified using heatand-moisture exchangers or humidifiers. ${ }^{9}$

Another physiological mechanism that is key to ventilation is airflow resistance. Resistance to air flow through a tube, represented by the Poiseuille equation, is directly proportional to the length, while being inversely proportional to the radius of the tube raised to the fourth power, when the flow is laminar. ${ }^{11}$ When the flow is turbulent (diameter of tube is $<10 \mathrm{~mm}$ ), the resistance becomes inversely proportional to the radius raised to the fifth power. Hence, this illustrates how small reductions in radius cause large increases in resistance. ${ }^{9}$ Theoretically, tracheostomy tubes should reduce airflow resistance. However, this is not the case because of the smaller radius (inner diameter of $7 \mathrm{~mm}$ ) of the tubes. Moreover, decreasing airflow resistance would allow an enhanced expiratory flow, and this would lower the probability of an intrinsic positive end-expiratory pressure (PEEP) developing. PEEP is the maintenance of a higher alveolar pressure compared to the atmospheric pressure at the end of expiration. ${ }^{13}$ This could be intrinsic (spontaneous breathing leading to incomplete exhalations) or extrinsic (applied via MV)..$^{14}$

Tracheostomy insertion could be an elective or emergency procedure and for short- or long-term use. There are two common methods of carrying out the insertion - surgical or percutaneous. Surgical tracheostomy starts with skin incision, followed by the retraction of strap muscles and thyroid isthmus. Finally, a stoma is created between the second and third tracheal rings. In percutaneous, the insertion is done at the bedside and is comparatively quicker. This approach includes a needle inserted into the trachea, a guide wire and a bronchoscope. ${ }^{15,16}$

\section{TIMING OF TRACHEOSTOMY}

\section{Results}

Various studies have looked into this topic with their own unique definitions of when it is considered early and late to perform a tracheostomy. Nevertheless, it is vital to acknowledge that each study was carried out on different patients for different indications, as shown in Table 1.

\begin{tabular}{|c|c|c|c|c|}
\hline Study & $\begin{array}{c}\text { Definition of early vs } \\
\text { late tracheostomy } \\
\text { (days) }\end{array}$ & $\begin{array}{c}\text { Number of } \\
\text { patients in early } \\
\text { vs late groups }\end{array}$ & $\begin{array}{c}\text { Indications for } \\
\text { tracheostomy }\end{array}$ & $\begin{array}{c}\text { Tracheostomy rate } \\
\text { (number (\%)) in early } \\
\text { vs late groups }\end{array}$ \\
\hline $\begin{array}{c}\text { Saffle et al. } \\
(2002)^{17}\end{array}$ & $2-4$ vs 14-16 & 21 vs 23 & Burns & $\begin{array}{c}21(100 \%) \text { vs } \\
16(70 \%)\end{array}$ \\
\hline $\begin{array}{c}\text { Rumbak et al. } \\
(2004)^{18}\end{array}$ & $\leq 2$ vs >14 & 60 vs 60 & $\begin{array}{c}\text { Respiratory failure, } \\
\text { severe sepsis }\end{array}$ & $\begin{array}{c}60(100 \%) \text { vs } \\
50(83 \%)\end{array}$ \\
\hline $\begin{array}{c}\text { Romero et al. } \\
(2009)^{19}\end{array}$ & $\leq 7$ vs >7 & 71 vs 81 & $\begin{array}{c}\text { Traumatic spinal cord } \\
\text { injury }\end{array}$ & $\begin{array}{c}71(100 \%) \text { vs } \\
81(100 \%)\end{array}$ \\
\hline $\begin{array}{c}\text { Terragni et al. } \\
(2010)^{20}\end{array}$ & $6-8$ vs 13-15 & 209 vs 210 & $\begin{array}{c}\text { Respiratory failure, } \\
\text { neurological and } \\
\text { cardiovascular disease }\end{array}$ & $\begin{array}{c}145(69 \%) \text { vs } \\
119(57 \%)\end{array}$ \\
\hline $\begin{array}{c}\text { Young et al. } \\
(2013)^{6}\end{array}$ & $\leq 4$ vs $>10$ & 451 vs 448 & $\begin{array}{c}\text { Pulmonary and } \\
\text { gastrointestinal } \\
\text { conditions }\end{array}$ & $\begin{array}{c}418(93 \%) \text { vs } \\
204(46 \%)\end{array}$ \\
\hline $\begin{array}{c}\text { Lee et al. } \\
(2016)^{21}\end{array}$ & $<14$ vs $\geq 14$ & 61 vs 50 & $\begin{array}{c}\text { Cardiovascular and } \\
\text { respiratory disease }\end{array}$ & $61(100 \%)$ vs \\
\hline
\end{tabular}

Table 1: Summary of the included studies on early versus late tracheostomy (adapted from references 6, 17-21) 


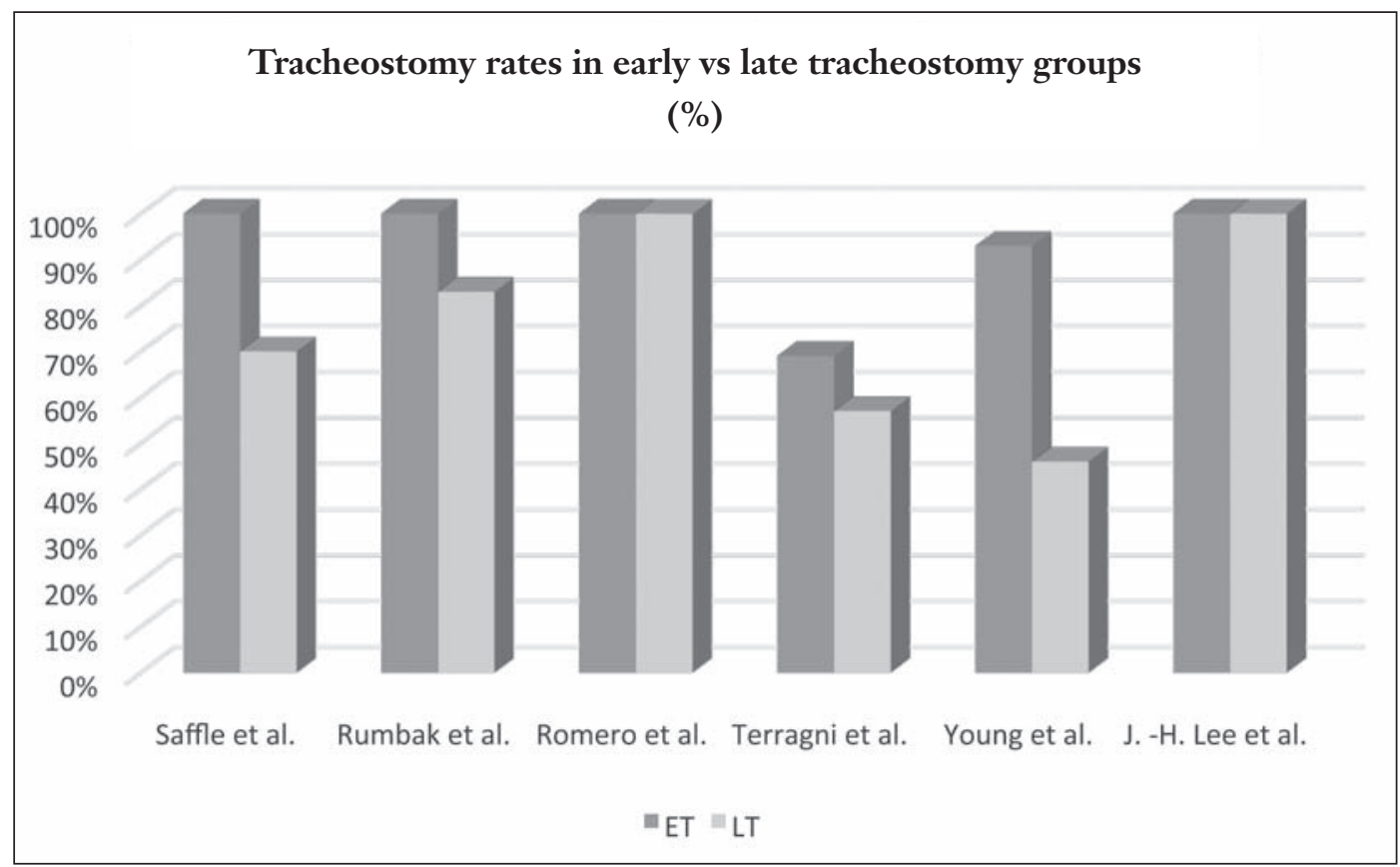

Figure 3: Tracheostomy rates between early and late tracheostomy groups in all included studies (adapted from references $6,17-21$ )
The largest study conducted out of these studies is the one carried out by Young et al. in $2013,{ }^{6}$ named the TracMan (Tracheostomy Management) study. Patients were randomised (1:1) to early tracheostomy (ET) and late tracheostomy (LT) groups. ET was defined as within 4 days after admission on MV. These patients were identified by the clinicians as likely to need at least 7 more days of MV. While LT was defined as performing it on day 10 or later, and then only if the clinician deemed it to still be indicated. ${ }^{6}$ There were 451 patients assigned to the ET group, of which $93 \%$ received a tracheostomy and 448 patients assigned to the LT group, of which $46 \%$ received a tracheostomy (see Fig. 3). So the LT group had 244 patients who never had a tracheostomy due to various reasons listed in Table 2 . The primary outcome of this study was to look at the 30-day mortality rate, and it presented with no statistical difference between the two groups. Other outcomes are depicted in Table 3.

\begin{tabular}{|c|c|}
\hline $\begin{array}{c}\text { Reason for not performing a } \\
\text { tracheostomy in LT group }\end{array}$ & $\begin{array}{c}\text { Number of } \\
\text { patients (\%) }\end{array}$ \\
\hline $\begin{array}{c}\text { Discharged alive from the critical } \\
\text { care unit by day } 10\end{array}$ & $89(19.6 \%)$ \\
\hline $\begin{array}{c}\text { Remained in the critical care unit but } \\
\text { no longer required ventilator support }\end{array}$ & $78(17.2 \%)$ \\
\hline Died & $54(11.9 \%)$ \\
\hline Remained too unstable & $11(2.4 \%)$ \\
\hline Had treatment withdrawn & $2(0.4 \%)$ \\
\hline No recorded reason & $10(2.2 \%)$ \\
\hline
\end{tabular}

Table 2: Reasons on why tracheostomy was not performed on certain patients assigned to the LT group in the TracMan study (adapted from reference 6)
Furthermore, these studies had specific primary and secondary outcomes to measure (seen in Table 3). The majority of these studies illustrated a shorter duration of MV, ICU stay, sedation, a lower probability of acquiring pneumonia and lower mortality rates (both $\leq 2$ months and $>2$ months) in the ET group.

In addition, other findings involved recognising the complications that followed the procedure of tracheostomy in patients in both groups, ET and LT (seen in Table 4). The most common complications were bleeding and infection of the surrounding skin. However, there were more severe risks, such as airway accidents, tracheomalacia (widening of the trachea due to flaccidity of the supporting cartilage rings) $)^{22}$ and vocal injury. ${ }^{3}$

Alongside these studies, another consideration is the comparison between prolonged TI, which is attributed to the LT group due to these patients being intubated until a tracheostomy is performed, and ET (seen in Table 5). ${ }^{23}$ It presents the ET group to be more beneficial than the continued-TI group, in terms of lesser number of days of $\mathrm{MV}$, quicker weaning time, lower probability of acquiring pneumonia, and lastly, a perfect liberation rate from MV.

\section{Discussion}

These results suggest that ET has more benefits compared to performing a LT, regardless of the varying definition of early and late. Firstly, the tracheostomy rates question the necessity of performing one in a critically ill patient. As in the study by Young et al., it is illustrated how only $46 \%$ of patients in the LT group had a tracheostomy performed. ${ }^{6}$ This shows that more than half of the patients did not require it after day 10 (definition for LT) for various reasons as seen in Table 2. This demonstrates that if the clinician had held back on performing a tracheostomy in the early stages, the patient could have avoided the risks attached with performing a tracheostomy. ${ }^{21}$ This sheds light on how it could be beneficial to restrain from performing an ET, unless if it is an emergency, to observe how the patient's condition develops. 


\begin{tabular}{|c|c|c|c|c|c|c|}
\hline Study & $\begin{array}{c}\text { Mean } \\
\text { duration of } \\
\text { mechanical } \\
\text { ventilation } \\
\text { post- } \\
\text { tracheostomy, } \\
\text { early vs late } \\
\text { groups /days } \\
\text { (SD) }\end{array}$ & $\begin{array}{l}\text { Mean } \\
\text { duration } \\
\text { of ICU } \\
\text { stay post- } \\
\text { tracheostomy, } \\
\text { early vs late } \\
\text { groups /days } \\
\text { (SD) }\end{array}$ & $\begin{array}{l}\text { Mean } \\
\text { duration of } \\
\text { sedation post- } \\
\text { tracheostomy, } \\
\text { early vs late } \\
\text { groups /days } \\
\text { (SD) }\end{array}$ & $\begin{array}{l}\text { Acquired } \\
\text { pneumonia } \\
\text { post- } \\
\text { tracheostomy, } \\
\text { early vs late } \\
\text { groups / } \\
\text { patients (\% } \\
\text { of total in the } \\
\text { group) }\end{array}$ & $\begin{array}{l}\text { Mortality ( } \leq 2 \\
\text { months) post- } \\
\text { tracheostomy, } \\
\text { early vs late } \\
\text { groups / } \\
\text { patients (\% } \\
\text { of total in the } \\
\text { group) }\end{array}$ & $\begin{array}{c}\text { Mortality ( }>2 \\
\text { months) post- } \\
\text { tracheostomy, } \\
\text { early vs late } \\
\text { groups / } \\
\text { patients (\% } \\
\text { of total in the } \\
\text { group) }\end{array}$ \\
\hline $\begin{array}{l}\text { Saffle } \\
\text { et al. } \\
(2002)^{17}\end{array}$ & $\begin{array}{c}35.5(4.5) \text { vs } \\
31.4(5.2)\end{array}$ & N/A & N/A & $\begin{array}{c}21(100 \%) \text { vs } \\
22(96 \%)\end{array}$ & $\begin{array}{c}17(81 \%) \text { vs } \\
17(74 \%)\end{array}$ & N/A \\
\hline $\begin{array}{l}\text { Rumbak } \\
\text { et al. } \\
(2004)^{18}\end{array}$ & $\begin{array}{l}7.6(4.0) \mathrm{vs} \\
17.4(5.3)\end{array}$ & $\begin{array}{l}4.8(1.4) \text { vs } \\
16.2(3.8)\end{array}$ & $\begin{array}{l}3.2(0.4) \text { vs } \\
14.1(2.9)\end{array}$ & $\begin{array}{c}3(5 \%) \text { vs } 15 \\
(25 \%)\end{array}$ & $\begin{array}{c}19(32 \%) \text { vs } \\
37(62 \%) \\
\text { (at } 30 \text { days) }\end{array}$ & N/A \\
\hline $\begin{array}{l}\text { Romero } \\
\text { et al. } \\
(2009)^{19}\end{array}$ & $\begin{array}{l}22.1(1.2) \text { vs } \\
34.0(3.3)\end{array}$ & $\begin{array}{c}30.6(1.6) \text { vs } \\
39.3(3.0)\end{array}$ & N/A & $\begin{array}{c}53(74.6 \%) \text { vs } \\
59(72.8 \%)\end{array}$ & N/A & $\begin{array}{c}1(1 \%) \text { vs } \\
5(6 \%)\end{array}$ \\
\hline $\begin{array}{l}\text { Terragni } \\
\text { et al. } \\
(2010)^{20} \\
\end{array}$ & N/A & N/A & N/A & $\begin{array}{c}30(14 \%) \text { vs } 44 \\
(21 \%)\end{array}$ & $\begin{array}{c}55(26 \%) \text { vs } \\
66(31 \%) \\
\text { (at } 28 \text { days) }\end{array}$ & $\begin{array}{l}72(50 \%) \text { vs } \\
75(57 \%) \\
\text { (in } 1 \text { year) }\end{array}$ \\
\hline $\begin{array}{l}\text { Young } \\
\text { et al. } \\
\left(2013^{6}\right.\end{array}$ & $\begin{array}{c}12.9(11.8) \mathrm{vs} \\
16.1(14.7)\end{array}$ & $\begin{array}{l}13.0 \text { vs } 13.1 \text { in } \\
\text { survivors; } 9.3 \\
\text { vs } 10.4 \text { in non- } \\
\text { survivors }\end{array}$ & $\begin{array}{l}5.0 \mathrm{vs} \\
8.0 \mathrm{in} \\
\text { survivors; } 5.0 \\
\text { vs } 6.0 \text { in non- } \\
\text { survivors }\end{array}$ & N/A & $\begin{array}{c}139(31 \%) \text { vs } \\
141(32 \%) \\
\text { (at } 30 \text { days) }\end{array}$ & $\begin{array}{c}168(40 \%) \text { vs } \\
180(41 \%) \text { (in } \\
\text { hospital); } 207 \\
(46 \%) \text { vs } 217 \\
(49 \%) \text { (in } 1 \\
\text { year) }\end{array}$ \\
\hline $\begin{array}{l}\text { Lee et } \\
\text { al. } \\
(2016)^{21}\end{array}$ & $\begin{array}{l}1.6 \text { (NA) vs } \\
3.3 \text { (NA) }\end{array}$ & $\begin{array}{l}5.5 \text { (NA) vs } \\
11.0 \text { (NA) }\end{array}$ & N/A & $\begin{array}{c}1(2 \%) \text { vs } 2 \\
(4 \%)\end{array}$ & $\begin{array}{c}4(7 \%) \text { vs } \\
2(4 \%)\end{array}$ & $\begin{array}{l}18(30 \%) \text { vs } \\
20(40 \%) \\
\text { (in } 1 \text { year) }\end{array}$ \\
\hline
\end{tabular}

Table 3: Summary of the post-tracheostomy outcomes in the included studies based on ET vs LT (N/A: Not Applicable) (adapted from references $6,17-21$ )

\begin{tabular}{|c|c|}
\hline Study & Complications \\
\hline Saffle et al. $(2002)^{17}$ & $\begin{array}{c}\text { Most common were pneumonia, tracheoesophageal or tracheoarterial fistulas, } \\
\text { tracheal stenosis }\end{array}$ \\
\hline $\begin{array}{l}\text { Romero et al. } \\
\quad(2009)^{19}\end{array}$ & $\begin{array}{l}\mathrm{ET}-22(31 \%) \text { vs LT }-42(52 \%) \text {; ET is mainly due to bleeding and stoma } \\
\text { infection, while LT is due to concentric tracheal stenosis and tracheal granuloma }\end{array}$ \\
\hline $\begin{array}{l}\text { Young et al. } \\
\qquad(2013)^{6}\end{array}$ & $\begin{array}{c}\text { Overall complication rate was } 6.3 \% \text { (in both groups), most of which were bleeding } \\
\text { requiring IV fluids. }\end{array}$ \\
\hline $\begin{array}{l}\text { Lee et al. } \\
(2016)^{21}\end{array}$ & $\begin{array}{l}\text { No severe complications, but possible ones include accidental decannulation, } \\
\text { wound infection, erosion and abscess. }\end{array}$ \\
\hline
\end{tabular}

Table 4: Summary of complications following the tracheostomy procedure in the included studies (adapted from references 6, 17, 19, 21)

On the other hand, there were a larger number of outcomes to support the performance of an ET. Mean duration of MV post-tracheostomy proved to be longer for the LT group, with as much as 10 days in the study conducted by Rumbak et al. ${ }^{18}$ In addition, the mean length of stay in the ICU was reduced for the ET group, as shown in Table 3. This underlines how performing an ET could accelerate the patient's weaning and improve their general health status. Moreover, there was a reduction observed in sedative use in the ET group which aids in improving patient comfort and weaning. ${ }^{5}$

Another outcome analysed by these studies was ventilator-associated pneumonia (VAP). It would be hypothesised that incidence of VAP would be reduced by 


\begin{tabular}{|c|c|c|}
\hline $\begin{array}{c}\text { Clinical } \\
\text { outcomes }\end{array}$ & $\begin{array}{c}\text { Early } \\
\text { tracheostomy } \\
\text { / n=21 }\end{array}$ & $\begin{array}{c}\text { Continued- } \\
\text { translaryngeal } \\
\text { intubation } \\
/ \mathbf{n}=\mathbf{5 3}\end{array}$ \\
\hline $\begin{array}{c}\text { Total number } \\
\text { of days of MV } \\
\text { (IQR) }\end{array}$ & $11(9-26)$ & $13(8-21)$ \\
\hline $\begin{array}{c}\text { Total number } \\
\text { of days weaning } \\
\text { (IQR) }\end{array}$ & $3(1-11)$ & $6(3-14)$ \\
\hline $\begin{array}{c}\text { Number of } \\
\text { tracheostomies } \\
\text { performed (rate) }\end{array}$ & $21(100 \%)$ & $25(47 \%)$ \\
\hline Pneumonia (\%) & $3(14 \%)$ & $17(32 \%)$ \\
\hline $\begin{array}{c}\text { Successful } \\
\text { liberation from } \\
\text { MV (\%) }\end{array}$ & $21(100 \%)$ & $47(89 \%)$ \\
\hline $\begin{array}{c}\text { Survived after } \\
\text { the study }\end{array}$ & $21(100 \%)$ & $48(91 \%)$ \\
\hline
\end{tabular}

Table 5: Comparison of the clinical outcomes in the early tracheostomy group and in the continued-translaryngeal intubation group. [IQR = Interquartile range] (adapted from reference 23)

performing a tracheostomy and removing a prolonged TI. The results on VAP reveal that there is no significant reduction in its incidence in the ET group compared to the LT, as depicted in the Terragni et al. randomised trial $^{20}$. An additional outcome evaluated was the mortality rates, subdivided into within 2 months and after 2 months (such as 1-year mortality) of the procedure. These studies demonstrated that there was no significant difference in the mortality rates between the two groups. Thus, this shows that the decision of withholding a tracheostomy for the LT patients does not subject them to a dire state of consequent death. In addition, interestingly there is a significant reduction observed in the mortality rates $(\leq 2$ months) from the earliest to the latest study (Saffle et al. ${ }^{17}$ to Lee et al. ${ }^{21}$ ). This hints at a possible improvement in the surgical performance of the procedure or in the equipment used, such as tracheostomy tubes. Overall, the clinical outcomes that are influenced by the timing of tracheostomy are duration of $\mathrm{MV}$ and sedation, and length of stay in critical care units. ETs are associated with a quicker weaning process, removing the patient's critically ill status and allowing them to be independent.

In addition to these studies, it is vital to compare the use of tracheostomy and TI. Patients are usually on TI before a tracheostomy tube is inserted, until the clinician predicts the need for prolonged MV. ${ }^{3,5}$ Nevertheless, tracheostomy proves to be more advantageous compared to TI - in terms of lesser number of days of MV and for weaning, lower rates of VAP, and a greater rate of successful liberation from MV (seen in Table 5). Furthermore, tracheostomy has reputed benefits such as reduced laryngeal damage, which is caused by prolonged TI, better patient comfort based on lesser sedation needed, improved oral hygiene and improved ability to communicate. ${ }^{5,23}$ Hence, this underlines the impact that delaying a tracheostomy could have on the patient if they are predicted to need continued MV.

However, here lies the issue of prediction of who would require prolonged $\mathrm{MV}$. As of now, this vital decision lies in the hands of the clinician. ${ }^{5}$ There are no established guidelines to facilitate this decision, and this hampers the treatment of critically ill patients in the early stages of their illness. Most decisions depend on clinical criteria, which are often found to be unreliable and subjective. ${ }^{24}$

\section{Future directions}

As these above-mentioned studies highlight that an ET could be beneficial for the patient, the obstacle lies in determining who will be eligible and benefit most from an early procedure. This challenge could be resolved by determining the factors that could predict the need for prolonged MV. A study by Sanabria et al. ${ }^{24}$ aims to elicit predictive factors for prolonged intubation, longer than 7 days. This study included patients who required at least 48 hours of MV. Certain variables were associated with prolonged MV including age and diagnosis of surgical emergency in a patient with a medical condition. However, the predictive value of these variables were poor making the prediction process impossible. This outcome can be explained by the dynamic nature of critical care patients, with timely clinical changes. Nevertheless, this study did demonstrate that the probability for extubation is approximately $25 \%$ after day 8 of $\mathrm{MV}$, and around $18 \%$ after day 9 . Hence, this suggests that patients who reach these stages are viable candidates for a tracheostomy based on their low probability of extubation.

Another study, by Heffner et al., ${ }^{25}$ involved determining if there were any clinical features apparent after 7 days of $\mathrm{MV}$ that could be used to predict long-term intubation ( $>14$ days), and a subsequent tracheostomy. The study divided the patients into two groups - group 1 patients were successfully extubated in $\leq 14$ days after onset of acute respiratory distress syndrome (ARDS), whereas group 2 patients remained intubated $>14$ days. On day 7 of ARDS, certain clinical features were identified as distinct between the two groups, which were associated with a MV time of $\leq 14$ days:

$$
\begin{aligned}
& \text { Positive end-expiratory pressure }(\mathrm{PEEP}) \leq 10 \mathrm{~cm} \\
& \mathrm{H}_{2} \mathrm{O}
\end{aligned}
$$

$\mathrm{PaO}_{2} / \mathrm{PAO}_{2}$ (arterial oxygen pressure/alveolar oxygen pressure) ratio $>0.4$

A quick improvement in radiological findings (from a thorax $\mathrm{x}$-ray)

In addition, another study by Durbin et al. ${ }^{23}$ suggested an algorithm that could be used to identify who would require an ET (shown in Fig. 5). This amalgamation of clinical features can be used as a checklist to consider whether it may be necessary for a patient to receive an ET.

Hence, these certain clinical features could aid in a more timely conversion of TI to tracheostomy. However, there are various limitations such as the variables, in Heffner et al. ${ }^{25}$ study, are limited to respiratory conditions and hence would not be suitable for all other indications. Moreover, the algorithm suggested by Durbin et al. ${ }^{23}$ 


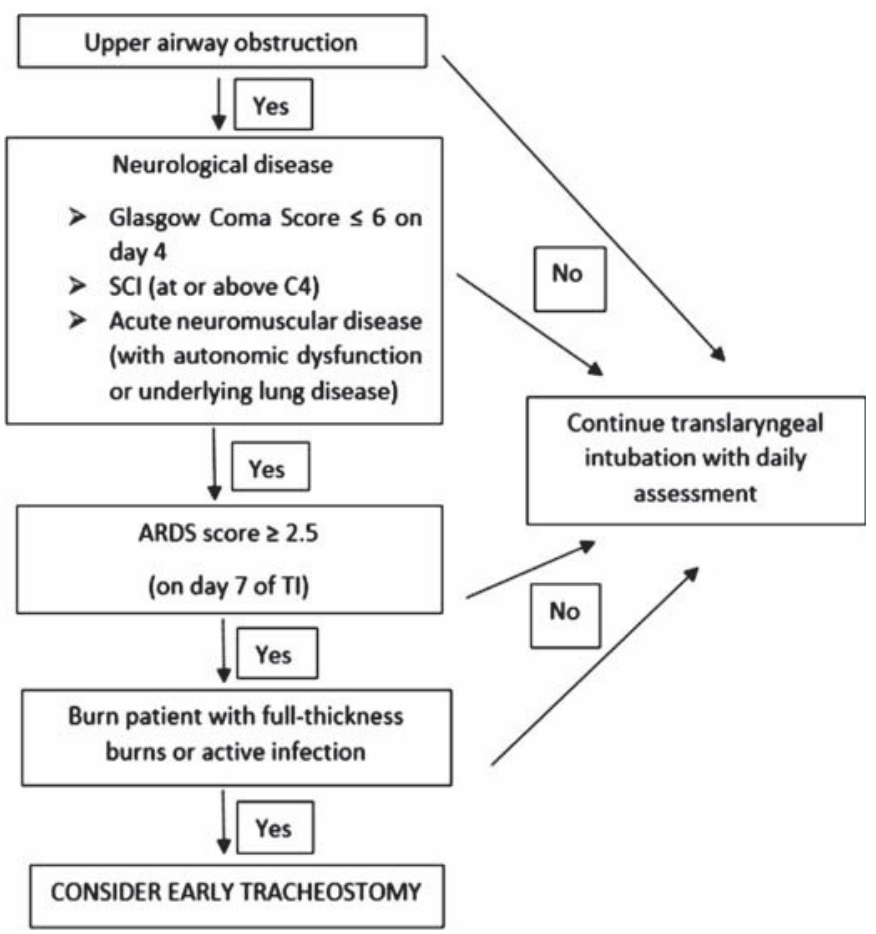

Figure 4: An algorithm suggesting predictive factors to perform an early tracheostomy (adapted from reference 23)

would not apply in all cases, as not all patients would present with those medical issues. Therefore, it remains elusive to acquire an objective framework to pinpoint who would require a prolonged $\mathrm{MV}$, and subsequently when to perform a tracheostomy.

\section{Limitations}

There are various limitations attached to this review. Firstly, the heterogeneous nature of all the studies limits the evaluation. Each study has their own unique definition on when it is considered early and late to perform a tracheostomy. In addition, each study has distinct indications and patients, such as Lee et al. ${ }^{21}$ looking solely at paediatric patients ( 1 month old -18 years old), while Romero et al. ${ }^{19}$ investigated traumatic SCI patients. Another major weakness is the subjective decisionmaking of the clinicians on deciding who would require prolonged MV. Moreover, bias may have influenced how the patients were selected for the studies and how they were split into the ET and LT groups. Alongside the subjective judgement of the clinician, other factors may also have been considered for a tracheostomy including the background lung function of the patient.

\section{CONCLUSION}

In conclusion, it is evident that performing a tracheostomy early in the course of one's illness may prove to be beneficial - in terms of having a reduction in the duration of sedation, a shorter stay in ICU, and a shorter weaning time. However, no significant change was observed in the VAP or mortality rates. In contrast, it is vital to acknowledge the risks and complications that come along with the procedure. This is coupled with how the tracheostomy rates indicate that more than half of the patients assigned to receive a tracheostomy later than 10 days never received one. ${ }^{5,6}$ Hence, if the clinicians had decided to wait and observe the patients' conditions, there would not have been a need for a tracheostomy and its risks.

A way of solving this dilemma is by recognising which patient would require prolonged MV. Unfortunately, the only answer available is a clinician's risk-benefit judgement. Moreover, this judgement is subjective and is shown to be poor in the early stages of one's critical condition, ${ }^{5}$ it also proves to be impossible with the alternating nature of critical care patients. Certain studies have proposed algorithms to decide who would require an ET, but their predictive value is poor and is not statistically significant to allow a clinician to confidently subject a patient to a tracheostomy. ${ }^{24,25}$ Hence, this portrays this decision to be individualised to each patient and his or her condition. ${ }^{6}$ Therefore, if possible in the future, an objective framework to predict prolonged ventilatory support would aid a clinician's decision to perform an early tracheostomy.

\section{REFERENCES}

1. Cheung NH, Napolitano LM.Tracheostomy: epidemiology, indications, timing, technique, and outcomes. Respir Care. 2014;59(6):895-915; discussion 916-899.

2. Stauffer JL. Complications of translaryngeal intubation. IN Tobin M. Principles and practice of mechanical ventilation. 3rd Ed. New York: McGaw Hill; 2013, chapter 39.

3. Durbin CG. Indications for and timing of tracheostomy. Respir Care. 2005;50(4):483-487.

4. Philpott C, Bennett A, Tassone P. Timing of tracheostomy in adult patients: potential ramifications are alarming. BMJ. 2005;331(7513):404.

5. Durbin, CG. Tracheostomy: why, when, and how? Respir Care. 2010;55(8):1056-1068.

6. Young D., et al. Effect of early vs late tracheostomy placement on survival in patients receiving mechanical ventilation: the TracMan randomized trial. JAMA.2013;309(20):2121-2129.

7. Andriolo BN., et al. (2015).Early versus late tracheostomy for critically ill patients. Cochrane Database Syst Rev 1: Cd007271.

8. Patwa A. Shah A. Anatomy and physiology of respiratory system relevant to anaesthesia. Indian Journal of Anaesthesia. 2015;59(9):533-541.

9. Epstein SK. Anatomy and physiology of tracheostomy. Respir Care. 2005;50(4):476-482.

10. Jackson C. Humidification in the upper respiratory tract: a physiological overview. Intensive Crit Care Nurs. 1996;12(1):27-32.

11. Kaminsky DA. What does airway resistance tell us about lung function? Respir Care. 2012; 57(1):85-96; discussion 96-89.

12. Quinn M, Bhimji SS. (2017) Anatomy, airway, anatomic dead space.IN StatPearls [Internet]. Available at: https://www.ncbi.nlm.nih.gov/books/ NBK442016/ (accessed 1.3.18).

13. Duncan AW. et al. PEEP and CPAP. Anaesth Intensive Care. 1986;14(3):236-250.

14. Caramez MP. et al. Paradoxical responses to positive end-expiratory pressure in patients with airway obstruction during controlled ventilation. Crit Care Med. 2005;33(7):1519-1528. 
15. Bhandary R. Niranjan N. (2011). Tracheostomy anaesthesia tutorial of the week 241. Available at: https://www.aagbi.org/node/1447 (accessed 1.3.18).

16. Mehta C. Mehta Y. Percutaneous tracheostomy. Annals of Cardiac Anaesthesia. 2017;20(5):19-25.

17. Saffle JR. et al. Early tracheostomy does not improve outcome in burn patients. J Burn Care Rehabil. 2002;23(6):431-438.

18. Rumbak MJ. et al. A prospective, randomized, study comparing early percutaneous dilational tracheotomy to prolonged translaryngeal intubation (delayed tracheotomy) in critically ill medical patients. Crit Care Med. 2004;32(8):1689-1694.

19. Romero J. et al. Tracheostomy timing in traumatic spinal cord injury. Eur Spine J. 2009;18(10):14521457.

20. Terragni PP. et al. Early vs late tracheotomy for prevention of pneumonia in mechanically ventilated adult ICU patients: a randomized controlled trial. JAMA. 2010;303(15):1483-1489.
21. Lee JH. et al. Effect of early vs. late tracheostomy on clinical outcomes in critically ill pediatric patients. Acta Anaesthesiol Scand. 2016;60(9):1281-1288.

22. Schwartz DS. (2017)Tracheomalacia. Available at: https://emedicine.medscape.com/article/426003overview (accessed 7.12.17).

23. Durbin CG. et al. Should tracheostomy be performed as early as 72 hours in patients requiring prolonged mechanical ventilation? Respir Care. 2010;55(1):7687.

24. Sanabria A. et al. Prediction of prolonged mechanical ventilation in patients in the intensive care unit: a cohort study. Colomb Med (Cali). 2013;44(3):184188.

25. Heffner JE, Zamora CA. (1990). Clinical predictors of prolonged translaryngeal intubation in patients with the adult respiratory distress syndrome. Chest. 1990;97(2):447-452.

Correspondence to: shadaba.ahmed@mbht.nhs.uk

\section{The Sir Richard Owen Lecture 2018}

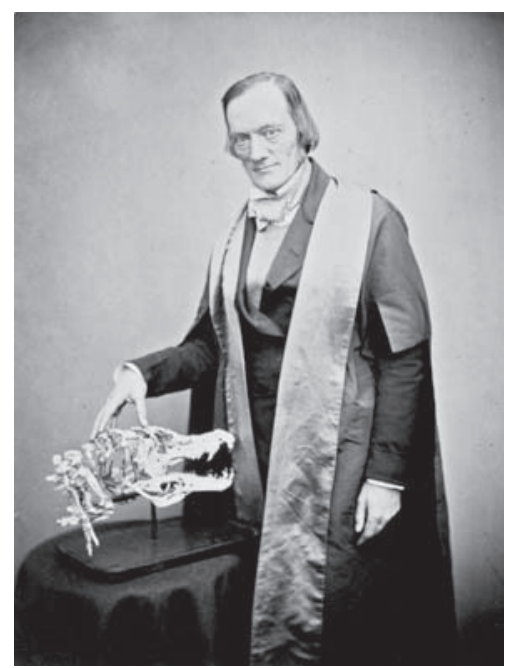

\section{Mr Francis Wells}

\section{Consultant Cardiothoracic Surgeon}

\section{The Heart of Leonardo}

Anatomy and the Italian Renaissance

Venue - Royal Lancaster Infirmary Education Centre

Time - from 6.00pm on Wednesday October 17th

\subsection{0 - Refreshments 6.30 - Lecture}

Tickets (no charge) from - Bryan Rhodes, Leigh Pinches, Laura Shepherd or Adam Taylor 